\title{
Technological Progress and Regress in Pre-industrial Times*
}

\author{
Shekhar Aiyar \\ International Monetary Fund University of Copenhagen \\ Omer Moav \\ Hebrew University, Royal Holloway University of London \\ Shalem Center, and CEPR
}

December, 2007

\begin{abstract}
This paper offers micro-foundations for the dynamic relationship between technology and population in the pre-industrial world, accounting for both technological progress and the hitherto neglected but common phenomenon of technological regress. A growing population engenders the endogenous adoption of new techniques that increase the division of labor. Conversely, technological progress supports an increasing population in the Malthusian environment. A transient shock to population or productivity, however, induces the neglect of some techniques rendered temporarily unprofitable, which are therefore not transmitted to the next generation. When the shock passes, the division of labor remains constrained by the smaller stock of knowledge, and technology has thereby regressed. A slow process of rediscovery is required for the economy to reach its previous level of technological sophistication and population size.
\end{abstract}

Keywords: Technological Regress, Technological Progress, Malthusian Stagnation, Division of Labor.

JEL Codes: O10, O33, O40, J11

\footnotetext{
*We would like to thank Theo Eicher, Christian Groth, Jacob Gyntelberg, Peter Howitt, Claus Thustrup Kreiner, Karl Gunnar Persson and David Weil for substantive discussions. We are also grateful to two anonymous referee's and seminar participants at Brown University, Hebrew University, Universidad Pompeu Fabra and the ASSET conference in Rethymno. The activities of EPRU (Economic Policy Research Unit) are financed through a grant from The Danish National Research Foundation. Omer Moav's research was supported by the Israel Science Foundation (grant No. 568/07). Contact: saiyar@imf.org, Carl.Johan.Dalgaard@econ.ku.dk, or omer.moav@huji.ac.il
} 
Inventions don't just get adopted once and forever; they have to be constantly practised and transmitted, or useful techniques may be forgotten.

Jared Diamond, Ten Thousand Years of Solitude, 1993.

\section{Introduction}

While much attention has been devoted to the study of ideas-based technological progress, and its role in economic growth, the economic literature is largely silent about the evolution of technology in pre-industrial times. In particular, there is no adequate account of the micro-foundations of technological change for all but the last few centuries. Moreover, the literature neither elucidates nor seriously engages with the fact that history contains several well documented instances of technological regress - lengthy periods during which important knowledge was lost. This paper attempts to document and remedy these omissions. It develops a theory encompassing both technological progress and regress that is consistent with the historical evolution of knowledge and population.

Why might an account of technological change in pre-industrial times be important? In part because of the sheer time-scales involved. Most of human history is characterized not by modern economic growth but by a Malthusian environment, so elucidating the processes that operated in that environment is crucial to an understanding of economic history. Moreover, it seems plausible that the evolution of technology in pre-industrial society may have affected the growth trajectories of countries in this era. ${ }^{1}$ Consistent with this view, Comin et al. (2006) uncover a striking correlation between measures of technological sophistication in 1000 B.C. and contemporary income levels.

The phenomenon of technological regress cannot be reconciled with standard macroeconomic models of innovation (Romer, 1990; Grossman and Helpman, 1991; Aghion and Howitt, 1992; Kortum, 1997; Weitzman, 1998; Olsson, 2000) or adoption (Nelson and Phelps, 1966; Eaton and Kortum, 1999). Knowledge in these theories is conceived as a stock which may stagnate but never shrinks. Nor is this surprising; the theories are built to explain the facts of the contemporary world, which is mostly characterized by purposive R\&D in rich countries, and the adoption of foreign technology by low-income countries. Accordingly, they do not model the interplay between population and technology that seems to characterize pre-industrial economies. ${ }^{2}$

\footnotetext{
${ }^{1}$ See Mokyr (2002) for an intriguing theory of how a changing nature of the accumulation of (technological) knowledge may have been a key ingredient in securing the take-off to sustained growth.

${ }^{2}$ Scale plays a role in some endogenous growth models, by affecting the incentives to invest
} 
A distinct strand of the literature explicitly models a pre-industrial environment, focusing on various aspects of Malthusian stagnation and on the transition from stagnation to growth. Some contributions invoke a reduced form effect of population on technological progress, without examining its micro-underpinning (Galor and Weil , 2000; Lucas, 2002; Hansen and Prescott, 2002). Others explicitly model growth as an outcome of specialization, but without modeling the dynamic interplay between technology and population (Goodfriend and McDermott, 1995; Fishman and Simhon, 2002; Kelly, 1997). None address or explain the fact of technological regress. ${ }^{3}$

This paper offers micro-foundations for the dynamics of technology in the pre-industrial world. It extends the applicability of ideas-based theories of growth to the epoch of human history preceding the Industrial Revolution, combining endogenous adoption of technology with endogenous population dynamics. It thereby accounts for not just technological progress, but also for the unexamined phenomenon - from the viewpoint of the current literature - of technological regress.

A central feature of the theory is that population growth engenders the endogenous adoption of techniques that facilitate the division of labor. Moreover, technological progress temporarily elevates the standard of living and induces population growth, thus driving income per capita back to the subsistence level. This positive feedback leads to convergence towards a Malthusian steady state, in which the division of labor is optimal for the endogenously determined population size, while income per capita is at a subsistence level, allowing for population replacement. On the path to the steady state, the positive feedback between population growth and the adoption of technology is restricted by the rate of technological progress, which is assumed to be an outcome of random discoveries.

Within this framework, the key to understanding technological regress is to recognize that the distinction between technology and human capital was much less clear cut in pre-industrial times than it is today. In modern societies it is feasible and often useful to treat the two as conceptually different. Human capital is inherently linked to the human body, whereas technological knowl-

in R\&D. However, the balanced growth paths typically predicted by endogenous growth models are incompatible with the Malthusian world. Moreover, the feedback from technological progress to the evolution of population is (as a rule) not addressed in the endogenous growth literature. Evidence, surveyed below, suggests that prior to industrialization, in the context of a Malthusian world, the evolution of technology and population dynamics are highly related.

${ }^{3}$ This literature is comprehensively surveyed by Galor (2005). In addition to those mentioned above, notable contributions include Kremer (1993), Doepke (2002), Galor and Moav (2002), de la Croix and Doepke (2003), Lagerlöf (2003), Hazan and Zoabi (2004), Cervellati and Sunde (2005). 
edge - "blueprints" - can be stored outside humans, in computers and books. But before the advent of the printing press and widespread literacy, technological knowledge would have to be embodied primarily in humans, and actively transmitted across generations in order to be preserved in society. This opens the possibility of technological regress. A transient negative shock to aggregate demand or supply, caused by a shock to population size or land productivity, would induce the neglect of techniques rendered temporarily unprofitable. However, techniques that were not transmitted to succeeding generations would be lost. The stock of technology would not immediately return to its former size when the shock passed. It would have regressed, to recover over time only as old techniques were rediscovered, or new techniques invented.

Numerous instances of lost knowledge and technological regress are to be found in the historical record. One example concerns a material that is ubiquitous in construction work to this day: cement. This technology embodies millennia of gradual improvements made by several civilizations. The ancient Egyptians used mortars of lime to build the pyramids, and the Chinese to build the Great Wall. Many improvements were made in cementitious compounds during the civilization of classical Greece. A high point in this incremental process was reached during the Roman Empire, when a mortar called 'Pozzolana cement' - which hardened under water - was developed. This compound enabled the construction of extremely large and durable structures such as aqueducts to conduct fresh water to Rome. Useful as Pozzolana cement undoubtedly was, during the centuries following the fall of the Roman Empire - the Early Middle Ages - the technology of its preparation was lost, and the quality of cement declined. Only in the early 13 th century was the technology relearned or reinvented.

Related to the loss of Pozzolana cement, architectural and engineering knowledge regressed considerably following the decline of the Roman empire. ${ }^{4}$ This regress is illustrated by the fact that, as late as the 15th century A.D., the inhabitants of Rome had built no canals to rival the aqueducts of over a millennium ago, and took their water from the "tainted, foul-smelling Tiber" (King, 2000). Most Romans of the time were ignorant even of the aqueducts' purpose, believing, for example, that the Acqua Claudia was used to import olive oil from

\footnotetext{
${ }^{4}$ This decline paralleled, and was probably linked to, the loss of the technique of perspective in art - the method of accurately representing three-dimensional objects on a two-dimensional surface. Greek vase paintings and marble reliefs show an understanding of perspective. The Romans made use of perspective in wall paintings, and the architect Vitruvius describes some of its principles. But during the Early Middle Ages, perspective disappeared from Western art, which came to be dominated by flat, highly stylized representations of Biblical scenes and characters. It was not until just before and during the Italian Renaissance that individuals such as Giotto, Brunelleschi and Masaccio rediscovered the laws and techniques of perspective.
} 
Naples.

Another striking illustration of regress is to be found in the history of Florence's famous cathedral, whose centerpiece is an enormous dome constructed without the support of external buttresses. When, in 1418, the city announced a competition for architectural models of the dome, it quickly came to be regarded as the architectural challenge of the century. The architect Brunelleschi is justly celebrated for discovering and implementing the techniques necessary for the dome's construction. Yet, an equally colossal dome - the Pantheon had stood in Rome for almost thirteen centuries at the time the architectural challenge was issued. ${ }^{5}$ But the techniques employed to construct the Pantheon had long been lost. ${ }^{6}$

The state of the medical sciences represents yet another example of decline. At the time that Alexandria's great library burned down, the frontier of medical technology was defined by the texts of Aristotle and Galen. But knowledge of these texts and the anatomical tradition they embodied was lost, or imperfectly preserved, in Western Europe, and medical technology regressed over the succeeding centuries. ${ }^{7}$

Of course, the Middle Ages also saw new innovations that added to the stock of existing knowledge. But considering the fundamental nature of the knowledge lost it seems reasonable to assert that the knowledge lost outweighed the knowledge gained, so that the average technological stock declined over the period.

This impression appears to be supported by the work of archaeologists and economic historians, and is embodied in the popular term often used to describe the period from Rome's decline to about the second millennium A.D.: "The Dark Ages". ${ }^{8}$ Grantham (1999) argues that the size of the decline in European income during the Early Middle Ages clearly indicates a reduced use of technologies available in the Roman era. Similarly, in his survey of the archaeological evidence on Roman technologies, Greene (1990) emphasizes that the occurrences of water-mills peaked during the 2nd and 3rd century A.D., thus indicating that this important technology was more widespread at the peak of

\footnotetext{
${ }^{5}$ The mean diameter of the Florentine dome is 143 feet and six inches, while the Pantheon spans 142 feet.

${ }^{6}$ In fact Brunelleschi himself made lengthy inspections of the Pantheon and other Roman buildings; these studies may have been crucial to his efforts to invent or reinvent the techniques he used in Florence. See Mainstone (1970) and King (2000).

${ }^{7}$ Much of this knowledge was preserved in the Islamic world. The old ideas were eventually reintroduced to the West by philosopher-physicians such as Averroes and Avicenna.

${ }^{8}$ In an influential contribution Finley (1965) argued to the contrary. That is, according to Finley antiquity was a period of modest progress whereas the Middle Ages were more innovative. Work by archaeologists has since then overturned the premises underlying Finley's conclusions; See Greene (2000) for point-by-point refutation of Finley's (1965) thesis.
} 
the Roman Empire than during the subsequent era. Moreover, as the survival of ancient technologies favors wet and inaccessible environments, Greene argues that the water-mill is likely to be representative of a much wider range of devices used in other contexts which simply did not survive long enough to be excavated. More recent work has provided support for Greene's conjecture. Technologies such as hydraulic mining techniques, construction in fired brick and the potter's wheel also seems to have been lost in the aftermath of the collapse of the Roman Empire (Wilson, 2002).

Examples of technological regress following the peak of the Roman Empire are ubiquitous, partly because the period is so well-documented relative to other historical civilizations in other regions of the world. For other societies the evidence is more difficult to marshal in such breadth and detail. Nonetheless, two specific non-European examples are worth considering: Tasmania and Easter Island.

Between the time that Tasmania was separated from mainland Australia some 10,000 years ago, and its first contact with Europeans in the mid 17th century, several crucial technologies were lost (Diamond, 1993). The list includes bone tools, such as needles, possibly the boomerang, and amazingly, the ability to catch fish. ${ }^{9}$

On Easter Island a period of major population decline and social disorder (most likely triggered by ecological collapse) was followed by technological regress; techniques for transporting and erecting the island's famous stone megaliths and for constructing seaworthy boats, and knowledge of a unique ideographic writing system, faded or vanished from the collective memory of society (Cottrell, 1964; Diamond, 1995; Diamond 2004).

The model developed in the subsequent section describes the evolution of an economy inhabited by individuals who live in overlapping generations. Technological progress is the outcome of optimally implementing random discoveries as an increasing variety of intermediate goods, to be interpreted as increased division of labor. At any given point in time the number of goods in existence, and therefore the amount of knowledge actively being used, is limited by two constraints: aggregate demand, as determined by the size of the population and factor productivity, and the state of knowledge regarding the production of intermediate goods. A unique feature of the theory is the economy's response to a negative shock - even a temporary shock - that disrupts the Malthusian

\footnotetext{
${ }^{9}$ Again, it is important to note that Tasmanians did in fact innovate during the period in question. About 4,000 years ago Tasmanians began visiting near by neighboring islands, indicating the discovery of a canoe-raft that made such excursions possible. But although Tasmanians continued to innovate over the period in question the archaeological consensus is that the loss of old technologies outweighed the gain of new ones.
} 
equilibrium by reducing the population size. ${ }^{10}$

When population shrinks, aggregate demand falls. Since the implementation of every different production technique entails a fixed cost, the demand constraint becomes binding, causing some techniques to become unprofitable at the margin. These techniques cease to be implemented. One of our key assumptions is that only the knowledge of utilized techniques is passed on to the next generation. Hence, those techniques that are out of use are not transmitted, and are thereby lost to subsequent generations. When the external shock passes, the division of labor is constrained by available technological knowledge, and output is therefore smaller. By implication population cannot fully recover in the short run, but is constrained by the growth of technology, which must occur through the gradual process of rediscovering old ideas or discovering new ones.

The model is characterized by a feedback loop, in which an increase in the division of labor (i.e. a greater variety of intermediate goods), allows for a rise in final output, thereby sustaining larger numbers of people. A two-way relationship between population and technology arises. Increased knowledge allows for a larger population, which in turn provides the economic incentives to implement new knowledge in the production process. Along the convergence path to the steady state there is a positive association between population size (and hence density) and technology. In the steady state the level of technological development and the size of population are determined by factors such as the amount of land available and its productivity. In spite of the fact that higher population density instigates a further division of labor it does not permanently allow for an improved standard of living due to the Malthusian feedback. Technological progress, by increasing income per capita, increases the size of the population, which pulls income per capita back to subsistence due to diminishing returns to labor.

The mutual positive interaction between population and technology is a central element of the theory, and may be thought of as a synthesis of Malthusian and Boserupian elements. ${ }^{11}$ The Malthusian part - technology stimulates pop-

\footnotetext{
${ }^{10}$ An immediately noteworthy common feature of the aforementioned instances of technological regress is that they all occurred during periods featuring major declines in the size of population. Following the collapse of the Roman Empire population underwent a significant decline (see Livi-Bacci, 1997). On Easter Island the population dropped during a few centuries to about a third of its original size.

${ }^{11}$ Boserup (1965) argues that population pressure leads to the adoption of intensive farming techniques and settled agriculture, which allows the division of labor to commence. The sweeping study by Diamond (1997) draws on these ideas. In contrast, the idea that population size matters for the speed of invention ("more people means more ideas") was developed by scholars such as Arrow (1962) and Phelps (1966). It has since found its way into innovation driven endogenous growth theory (see e.g., Jones, 2007). The model developed below does not involve this latter feature.
} 
ulation growth - is supported by recent empirical work on fertility patterns in pre-industrial societies (see Clark and Hamilton, 2004; Kelly, 2004; Botticini and Siow, 2005). Similarly, empirical support can be marshaled in favor of the "Boserupian" part. Hoffman (1996) shows that in different regions of France during the middle-ages, levels of total factor productivity were positively influenced by population density, while Simon and Sullivan (1989) document a positive impact from population on technological progress in England, over the period 1541-1850. At the world level, Kremer (1993) supports a positive bidirectional link between population and technology. Finally, employing data covering a cross section of 186 indigenous cultures Baker (2007) estimates a structural unified growth model and finds evidence in favor of a positive bidirectional association between population and technological sophistication. At a finer level Baker (2007) finds that the (Malthusian) impact from technology on population is quantitatively stronger than the countervailing (Boserupian) mechanism. ${ }^{12}$

Interestingly, the finding that technological progress responds less strongly to changes in population, in comparison to the reverse causation, is consistent with the mechanism underlying the theory developed in this paper. Under the assumption that the rate of technological innovation in pre-industrial times is small, population adjustment is rapid in comparison to the rate of technological adoption, even when the size of the population allows for rapid adoption of new techniques facilitating further division of labor.

The next section develops the model. In Section 3 we show how the model can be applied to the understanding of specific historical episodes. Section 4 concludes.

\section{The Model}

Consider an overlapping generations economy in a Malthusian environment. Land is a fixed factor of production, which is used in conjunction with intermediate goods to produce final output. Intermediate goods are produced using labor. Each intermediate firm is owned by a monopolist whose market power arises from the unique possession of the knowledge required for the production of that intermediate good. New ideas are discovered in each period, and each can potentially be used to produce a new variety, but they are only adopted

\footnotetext{
${ }^{12}$ Baker finds that a $10 \%$ increase in population density increases technology by $5 \%$, whereas a $10 \%$ increase in technology supports a $7 \%$ higher population density. Admittedly, Baker's study (like the other cited studies) cannot discriminate between the "Boserupian" adoptionview and the theory that more individuals produce more ideas, as suggested by Arrow (1962), Phelps (1966) and others. In practice, the detected positive impact from population on technological sophistication may well reflect both mechanisms.
} 
to the extent that the market supports further division of labor. Technological progress occurs when new ideas are adopted and the variety of intermediate goods expands.

\section{$2.1 \quad$ Individuals}

A generation of size $L_{t}$ is born at the beginning of each period and lives for two periods. In their first period of life individuals are idle children. In their second period of life - adulthood - they supply one unit of time to the labor market and allocate their entire income between consumption and raising children. Preferences are homothetic, and the cost of raising a child constant. Hence the size of population in period $t+1$ is proportional to total income in period $t$, regardless of its distribution across agents or the ownership of land: ${ }^{13}$

$$
L_{t+1}=\mu Y_{t}
$$

\subsection{Production of the Final Good}

The technology employed in the production of the final good is

$$
Z_{t}=K^{1-\alpha} \int_{0}^{N_{t}} x_{t}(j)^{\alpha} d j
$$

where $K$ denotes efficient units of land, and $x(j)$ is intermediate good $j, j \in$ $\left[0, N_{t}\right]$, while $N_{t}$ is the number of intermediate goods in period $t$. As usual, $N_{t}$ can be thought of as an index of technological sophistication. It is assumed that $\alpha \in(0,1 / 2)$ for reasons to be explained below.

Aggregate income available for consumption and child rearing is

$$
Y_{t}=Z_{t}-\theta_{t} N_{t}=K^{1-\alpha} \int_{0}^{N_{t}} x_{t}(j)^{\alpha} d j-\theta_{t} N_{t}
$$

where $\theta_{t}$ is a fixed cost associated with the production of each intermediate good.

The final good sector is competitive, and factor prices, measured in units of the final good, are therefore,

$$
\begin{aligned}
R_{t} & =\frac{d Y_{t}}{d K}=(1-\alpha) K^{-\alpha} \int_{0}^{N_{t}} x_{t}(j)^{\alpha} d j ; \\
p_{t}(j) & =\frac{d Y_{t}}{d x_{t}(j)}=\alpha K^{1-\alpha} x_{t}(j)^{\alpha-1},
\end{aligned}
$$

\footnotetext{
${ }^{13}$ An example of a set of primitives which leads to this result are the following: suppose the cost of raising a child is $\lambda$ units of the final good and that the utility of an adult individual in period $t$ is $u_{t}=(1-\beta) \log c_{t}+\beta \log n_{t}$, where $\beta \in(0,1) ; c_{t}$ is consumption and $n_{t}$ is the number of children. It follows from the optimization problem that the number of children in an household with income $y_{t}$, is $n_{t}=(\beta / \lambda) y_{t}$, and hence, the number of adults in the economy in the next period is $L_{t+1}=\mu Y_{t}$, where $\mu \equiv \beta / \lambda$.
} 
and the demand for $x_{t}(j)$ is,

$$
x_{t}(j)=K\left(\frac{\alpha}{p_{t}(j)}\right)^{1 /(1-\alpha)} .
$$

\subsection{Production of Intermediate Goods}

A knowledgeable individual - an individual with the knowledge required for the production of a specific intermediate good - can operate an intermediate good firm. The production function for each intermediate good is

$$
x_{t}(j)=l_{t}(j),
$$

where $l_{t}(j)$ is labor employed by firm $j$.

Each individual who operates an intermediate good firm in period $t$, transfers the knowledge at the end of the period to one individual of the next generation, for instance to one of the individual's offspring. If, however, the knowledge is not used for one period - i.e., if the variety of intermediate good corresponding to that knowledge is not produced - it is not transmitted to the next generation.

In light of equation (4) we can write the total revenue of the intermediate monopolistic firm as

$$
p_{t}(j) x_{t}(j)=\alpha K^{1-\alpha} x_{t}(j)^{\alpha},
$$

which implies that marginal revenue is

$$
\partial\left(p_{t}(j) x_{t}(j)\right) / \partial x_{t}(j)=\alpha^{2} K^{1-\alpha} x_{t}(j)^{\alpha-1}=\alpha p_{t}(j) .
$$

Since the marginal cost of producing a unit of intermediate good is the real wage (measured in units of the final good), $w_{t}$, it follows that the profit maximizing monopolist will charge the price

$$
p_{t}=\frac{w_{t}}{\alpha} \quad \text { for all } j .
$$

The optimal quantity can then be found by substituting the price into equation $(5)$ :

$$
x_{t}(j)=K\left(\frac{\alpha^{2}}{w_{t}}\right)^{1 /(1-\alpha)} \quad \text { for all } j .
$$

Finally, the profit associated with the production of an intermediate good is

$$
\pi_{t}=x_{t}\left(p_{t}-w_{t}\right)-\theta_{t},
$$

where $\theta_{t}$ is the fixed cost, in units of the final good, required to set up production. ${ }^{14}$

\footnotetext{
${ }^{14}$ Note that the added value of each intermediate producer is $x_{t} p_{t}-\theta_{t}$, and hence the total value added of the intermediate goods sector is $\int_{0}^{N_{t}} p_{t}(j) x_{t}(j) d j-\theta_{t} N_{t}$. The value added of the final sector is $Z_{t}-\int_{0}^{N_{t}} p_{t}(j) x_{t}(j) d j$, and hence aggregate income - the sum of added values is $Y_{t}=Z_{t}-\theta_{t} N_{t}$, as consistent with (3).
} 
Replacing with (9) and (10),

$$
\pi_{t}=(1-\alpha) \alpha^{\frac{1+\alpha}{1-\alpha}} w_{t}^{\frac{\alpha}{\alpha-1}} K-\theta_{t} \equiv \pi\left(w_{t}, \theta_{t} ; K\right) .
$$

$\theta_{t}$ is assumed to be increasing in the complexity of the economy. That is, it is assumed to rise with the number of varieties,

$$
\theta_{t}=\delta N_{t} .
$$

The introduction of a fixed cost that is increasing with $N_{t}$ is designed to generate a Malthusian steady-state characterized by constant population despite the arrival of new knowledge to the economy. As will become apparent, this structure allows a clearer exposition, and is not crucial for any of the main results, namely, the interaction between population growth and knowledge accumulation, as well as the neglect of techniques rendered temporarily unprofitable and the subsequent loss of knowledge. Removing this assumption would imply that the interaction between population growth and knowledge accumulation converges to a steady-state growth of population and technology, at a rate determined by the arrival of new ideas.

\subsection{The Level of Output}

There are two cases to be distinguished. The first case is where technological sophistication, or the degree of division of labor, is unconstrained by the knowledge embodied in society's denizens. The second is where the knowledge of individuals restricts the number of varieties that can be produced.

\subsubsection{Output When the Division of Labor is Unconstrained}

Let $H_{t}$ be the number of knowledgeable individuals - individuals who know how to produce a unique variety. If $H_{t}$ is sufficiently large, free entry ensures that profits are absent in equilibrium. Given the real wage, this pins down the number of varieties produced, denoted $N_{t}^{*}$ :

$$
\pi\left(w_{t}, \delta N_{t}^{*} ; K\right)=0 \Leftrightarrow(1-\alpha) \alpha^{\frac{1+\alpha}{1-\alpha}} w_{t}^{\frac{\alpha}{\alpha-1}} K=\delta N_{t}^{*} .
$$

Thus an unconstrained division of labor requires that $H_{t} \geq N_{t}^{*}$.

In equilibrium the labor market clears. As a result

$$
L_{t}=x_{t} N_{t}^{*}=\alpha^{\frac{2}{1-\alpha}} w_{t}^{\frac{1}{\alpha-1}} K N_{t}^{*},
$$

where the last equality follows from equation (10). Using equations (13) and (14) we can solve for the equilibrium number of varieties:

$$
N_{t}^{*}=\left(\frac{\alpha(1-\alpha) K^{1-\alpha} L_{t}^{\alpha}}{\delta}\right)^{\frac{1}{1+\alpha}} \equiv N^{*}\left(L_{t} ; K\right) .
$$


As is apparent, $N_{t}^{*}$ is an increasing concave function of $L_{t}$. Substituting the expression for $N_{t}^{*}$ into the labor market clearing condition, $L_{t}=N^{*} x_{t}$, yields the quantity of each variety produced in equilibrium

$$
x_{t}^{*}=K^{\frac{\alpha-1}{1+\alpha}}\left(\frac{\delta L_{t}}{\alpha(1-\alpha)}\right)^{\frac{1}{1+\alpha}} .
$$

Since we are dealing with a symmetrical equilibrium, it follows from (3) that

$$
Y_{t}=K^{1-\alpha} N_{t} x_{t}^{\alpha}-\delta N_{t}^{2}
$$

Accordingly, inserting equation (15) and (16) into this expression yields output as a function of population and land, when knowledge is not binding:

$$
Y_{t}^{*}=\Omega\left(K^{1-\alpha} L_{t}^{\alpha}\right)^{\frac{2}{1+\alpha}}
$$

where $\Omega=\delta^{\frac{\alpha-1}{1+\alpha}}\left([(1-\alpha) \alpha]^{\frac{1-\alpha}{1+\alpha}}-[(1-\alpha) \alpha]^{\frac{2}{1+\alpha}}\right)$.

Lemma $1 N^{*}\left(L_{t} ; K\right)<N_{t}^{\text {efficient }} \equiv \arg \max Y_{t}$.

Proof. Since the marginal product of each intermediate good is decreasing, a necessary condition for output maximization is a symmetric allocation of labor across intermediate goods: $x_{t}=L_{t} / N_{t}$ for any $N_{t}$. Hence, output as a function of $N_{t}$ is $Y_{t}=K^{1-\alpha} N_{t}\left(L_{t} / N_{t}\right)^{\alpha}-\delta N_{t}^{2}$, and therefore

$$
N_{t}^{e f f i c i e n t}=\left(\frac{(1-\alpha) K^{1-\alpha} L_{t}^{\alpha}}{2 \delta}\right)^{\frac{1}{1+\alpha}}
$$

and as follows from (15), noting that $\alpha<1 / 2, N^{*}\left(L_{t} ; K\right)<N_{t}^{\text {efficient }}$.

The competitive allocation is inefficient for any $\alpha \neq 1 / 2$. Under the restriction $\alpha<1 / 2, N^{*}\left(L_{t} ; K\right)$ is less then the efficient number of intermediate goods. This ensures that the adoption of new technologies, which would take place only if $N_{t}<N_{t}^{*}$, is efficient. Otherwise, if $\alpha>1 / 2$, technological progress could be associated with declining output.

\subsubsection{Output When the Division of Labor is Constrained}

If the number of knowledgeable individuals is less than the unconstrained equilibrium number of firms, $H_{t}<N^{*}\left(L_{t} ; K\right)$, the profit of the marginal firm is strictly positive and therefore the number of intermediate good firms, $N_{t}$, is equal to $H_{t}$. The production of each firm, $x_{t}$, is determined in the labor market,

$$
x_{t}=L_{t} / H_{t}
$$


Consequently it follows from (3) that

$$
Y_{t}=K^{1-\alpha} H_{t}^{1-\alpha} L_{t}^{\alpha}-\delta H_{t}^{2} .
$$

In sum, as follows from (17) and (19),

$$
Y_{t}=\left\{\begin{array}{lll}
K^{1-\alpha} H_{t}^{1-\alpha} L_{t}^{\alpha}-\delta H_{t}^{2} & \text { if } & H_{t}<N^{*}\left(L_{t} ; K\right) \\
\Omega\left(K^{1-\alpha} L_{t}^{\alpha}\right)^{\frac{2}{1+\alpha}} & \text { if } & H_{t} \geq N^{*}\left(L_{t} ; K\right)
\end{array} \equiv Y\left(L_{t} ; H_{t}, K\right) .\right.
$$

Note that, by Lemma $1, \partial Y\left(H_{t}, L_{t} ; K\right) / \partial H_{t} \geq 0$. More knowledge cannot lead to declining output.

\subsection{Knowledge Accumulation}

There exists a positive (but very low) probability that individuals in the economy discover a new variety at the beginning of their adult period of life (one can interpret these discoveries as an outcome of individuals actively searching for knowledge, since as long as $H_{t}<N_{t}^{*}$ there is a positive return to a discovery of a new variety). Hence it follows from the law of large numbers that the rate of discovery is $\gamma\left(L_{t}\right)$, where $\gamma^{\prime}\left(L_{t}\right)>0$. However, because the effect of population size on the rate of discovery of new ideas plays no role in the model, it is convenient - for expository purposes - to assume a constant rate $\gamma$. Hence, as long as $H_{t}<N_{t}^{*}$,

$$
H_{t+1}=(1+\gamma) H_{t} .
$$

As demonstrated earlier, if the division of labor is constrained by the stock of ideas, new ideas will always be adopted. Thus if $H_{t}<N_{t}^{*}$ the rate of technological change $N_{t+1} / N_{t}$ equals the rate of knowledge accumulation. It is assumed, as consistent with pre-industrial development, that $\gamma$ is small in comparison to the rate of population adjustment in a Malthusian economy. The evolution of population is discussed below.

\subsection{The Evolution of Population and Technology}

If knowledge is not binding the evolution of population follows from (1) and

$$
L_{t+1}=\mu Y_{t}^{*}=\mu \Omega\left(K^{1-\alpha} L_{t}^{\alpha}\right)^{\frac{2}{1+\alpha}} \equiv \phi^{*}\left(L_{t} ; K\right) .
$$

Proposition 2 If $N_{t}=N^{*}\left(L_{t} ; K\right)$ for all $t$, there exists a unique non-trivial globally stable steady state of population, $\bar{L}(K)=\Lambda K^{2}$ where $\Lambda=(\mu \Omega)^{\frac{1+\alpha}{1-\alpha}}$.

Proof. Follows from the properties of $\phi^{*}\left(L_{t} ; K\right)$. 
From (15) and Proposition 2, the steady state level of $N^{*}\left(L_{t} ; K\right)$ is

$$
\bar{N}=N^{*}(\bar{L}(K) ; K)=\left(\frac{\alpha(1-\alpha) \Lambda^{\alpha}}{\delta}\right)^{\frac{1}{1+\alpha}} K \equiv \bar{N}(K) .
$$

It follows from Proposition 2 that the population size is ultimately constrained by Malthusian forces. Once the economy is in its steady state, $L_{t}=\bar{L}$ and $N_{t}=\bar{N}$, additional technological knowledge - further division of labor - is not implemented.

For any $H_{t}<\bar{N}(K),(1)$ and (20) imply that the evolution of population is given by

$$
L_{t+1}=\mu Y\left(L_{t} ; H_{t}, K\right) \equiv \phi\left(L_{t} ; H_{t}, K\right) .
$$

As follows from Lemma $1, \phi\left(L_{t} ; H_{t}, K\right) \leq \phi^{*}\left(L_{t} ; K\right)$.

Lemma 3 There exists a unique non-trivial conditional steady state level of population for any $H_{t}<\bar{N}(K)$, denoted $\tilde{L}\left(H_{t} ; K\right)$, where $\tilde{L}\left(H_{t} ; K\right)<\bar{L}(K)$, and $N^{*}\left(\tilde{L}\left(H_{t} ; K\right) ; K\right)>H_{t}$.

Proof. Follows from the properties of (20), noting that, as follows from Lemma 1 , if $H_{t}<N^{*}\left(L_{t} ; K\right)$, then $\phi\left(L_{t} ; H_{t}, K\right)<\phi^{*}\left(L_{t} ; K\right)$.

Lemma 3 implies that if the adoption of new technologies is constrained by knowledge, population growth is also constrained. Moreover, $N^{*}\left(\tilde{L}\left(H_{t} ; K\right) ; K\right)>$ $H_{t}$, implies the following corollary:

Corollary 4 If $H_{t}=N^{*}\left(L_{t} ; K\right)<\bar{N}(K)$, i.e., $L_{t}<\bar{L}(K)$, then, $L_{t+1}>L_{t}$.

The Corollary implies that for $L_{t}<\bar{L}(K)$, and $N_{t}=N^{*}\left(L_{t} ; K\right)$, output is at a level above population replacement, allowing for population growth. It further follows that as long as $L_{t}<\bar{L}(K)$, new varieties are adopted in each period.

The next proposition, therefore, follows directly from Lemma 2 and Corollary 4.

Proposition $5 \bar{L}(K)$ is the unique globally stable steady state of population.

The interaction between population and technology implies a dynamic process converging to the long-run steady state of population, $\bar{L}(K)$, and technology, $\bar{N}(K)$. In particular, there is a positive feedback between population and technology. For any level of technology below $\bar{N}(K)$, population is converging to a level which is sufficient to generate the incentive for further adoption of new discoveries, whereas new discoveries raise output, supporting a larger population. 
In particular, under the assumption that technological progress, $\gamma$, is small in comparison to population adjustment rate, it follows that for any level of knowledge below the long run level, $H_{t}<\bar{N}(K)$, population is governed by $L_{t+1}=\phi\left(L_{t} ; H_{t}, K\right)$, and is converging to $\tilde{L}_{t}=\tilde{L}\left(H_{t} ; K\right)$. Since, as established in Lemma 3 , the optimal division of labor, once population has adjusted, is larger than the existing level of technology, $N^{*}\left(\tilde{L}_{t} ; K\right)>H_{t}$, the rise in population size allows for further division of labor and adoption of technology. The adoption of technology - which tracks the rise in $H_{t}$ - increases the conditional steady state $\tilde{L}_{t}$, leading to the positive feedback between population and technology in the convergence to the long run steady state $\bar{L}(K)$ and $\bar{N}(K)$.

\subsection{Technological Regress}

Consider an economy in its long-run Malthusian steady state with population $L=\bar{L}(K)$ and the number of intermediate goods $N=\bar{N}(K)$. This is depicted in Figure 1. Suppose that a temporary shock reduces $K$; a drought or some other natural disaster which negatively impacts on the productivity of land. The consequent reduction in aggregate income implies a smaller population in the next period. As a result of the decline in population to, say, $L_{0}$, depicted in Figure 1, the number of varieties produced falls due to the reduction in the size of the market; $N_{t}$ declines to its optimal level given the new population size, $N^{*}\left(L_{0}\right) \cdot{ }^{15}$

Techniques that are not used for production in a particular period are not transmitted to the next generation, and knowledge is lost. Hence, even if in the next period $K$ returns to its original level, technology will not fully recover. Consequently, population will not recover to its initial level $\bar{L}(K)$, but to a temporary conditional steady state, depicted in Figure 1 as point $\tilde{L}\left(N^{*}\left(L_{0}\right) ; K\right)$. This conditional steady state is characterized by both smaller population and regressed technology relative to the initial equilibrium. A full recovery to the initial equilibrium will be constrained by a slow process of new discoveries, or the rediscovery of techniques that were once used in production but were abandoned and losed through disuse. As depicted in the figure, a full recovery would depend on the rate of knowledge accumulation, $\gamma$, captured by $\phi$ shifting gradually upwards as knowledge accumulates.

If the economy is characterized by a sufficiently rapid rate of discovery the speed of adjustment back to the original steady state could be rapid; new ideas

\footnotetext{
${ }^{15}$ Alternatively, one could think of a temporary negative shock such as an epidemic which directly reduces population. Note that while death of people who are the sole holders of a productive technique could generate loss of knowledge, in our mechanism it is the decline in population size that reduces the scope for the division of labor, and thereby brings about the neglect of productive techniques, that are forgotten in the following period.
} 


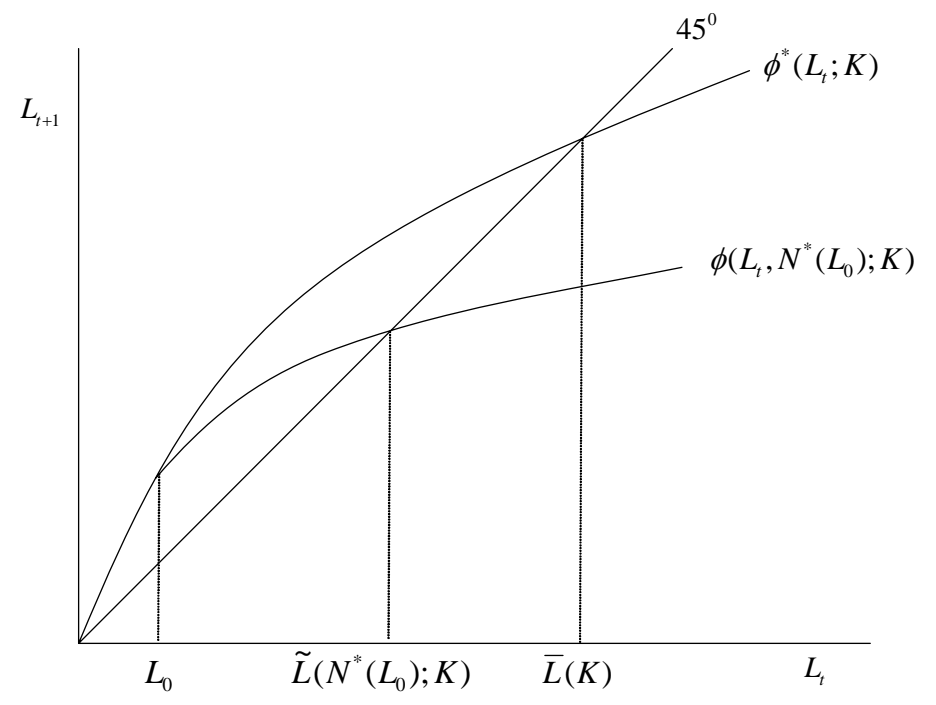

Figure 1: A shock to population at the steady state places the economy at $L_{0}$. Knowledge declines to $N^{*}\left(L_{0}\right)$, and population recovers to $\tilde{L}\left(N^{*}\left(L_{0}\right) ; K\right)$. Recovery to $\bar{L}(K)$ is limited by the rate of technological progress.

will then simply replace the knowledge lost during the decline, and the population will recover by way of standard Malthusian dynamics. However, if $\gamma$ is small, as seems plausible in the context of pre-industrial societies, the knowledge constraint will be binding, and, recovering fully from the temporary shock will be a lengthy process.

Accordingly, It is this feature of the model - the a slow rate of innovation is important in that explains explaining why technology may remain well below some past benchmark over an extended period of time. That is, it provides the context within which our central mechanism becomes relevantit elucidates the historically well-supported persistence of technological regress. The crux of the mechanism is our close identification of human capital with the stock of technology, and the assumption that knowledge is not transmitted if it is not used. If knowledge were a stock that remained constant even as population shrunk and some varieties were abandoned, then both population and technology would speedily recover to the initial steady state once the shock had passed. Our model, however, emphasizes that knowledge that is not transmitted is effectively lost. Therefore the recovery of both population and technology are constrained by knowledge, even when the temporary shock has abated. 


\section{Understanding Technological Regress in Pre- Industrial Societies}

\subsection{The Early Middle Ages}

The model described in the previous section may be employed to analyze specific examples of technological regress. The model predicts that a major decline in population - either directly through war, invasion, or epidemic, or indirectly through a negative shock to productivity caused by natural disaster, environmental degradation or social disorder - leads to a decline in aggregate demand and a corresponding reduction in the division of labor. Consequently, previously useful ideas are no longer profitable and cease to be transmitted across generations. Aggregate technological knowledge regresses. For output and population to recover to their initial level, a long period of rediscovering old technologies or discovering new alternative technologies is required. These features are broadly consistent with the economic and social history of the Early Middle Ages.

During and after the slow demise of the Roman Empire, the European population shrunk dramatically. Figure 2 shows the estimated population of Europe from the year 0 to 1200 A.D, measured relative to its level during the period 0-200. ${ }^{16}$ After the collapse of the Western part of the Roman Empire, the European population declines to nearly half its size before recovery sets in. Only early in the second millennium does the European population reach its level from Roman times.

Interestingly, the empirical record on technological innovations over the period appears to mirror the evolution of population, as also illustrated in Figure 2. Sorokin (1962) reports estimates of the number of major innovations made during the period 3500 B.C. -1908 A.D. The underlying source of the data tabulated in Sorokin's book is Ludwig Damstaedter's "Handbuch zur Geschichte der Naturwissenschaften und der Technik" from 1908. Damstaedter's work is based on the joint efforts of 26 German specialists, from a variety of fields. According to Sorokin, the data not only encapsulate pioneering creations and achievements, but also the individual steps required for the same. ${ }^{17}$ On the basis of this source Figure 2 displays the average number of inventions made

\footnotetext{
${ }^{16}$ The intervals are defined by data availability; estimates for population exist for year 0 , 200, 600, 1000 and 1200. Averages have therefore been taken to give an impression of the evolution of population during this 1200 year period; if population changed about linearly over the sub-periods the numbers in the Figure are reasonable estimates of mid-point population sizes.

${ }^{17}$ Upto $600 \mathrm{AD}$ the data refer to the entire world with the exception of China, India and a few other oriental countries. In practice, however, the bulk of the innovations counted are of European origin, for the simple reason that these are more frequently recorded (Sorokin, 1962, p.131-133). From 600 onwards the data only refer to Western Europe and the US.
} 


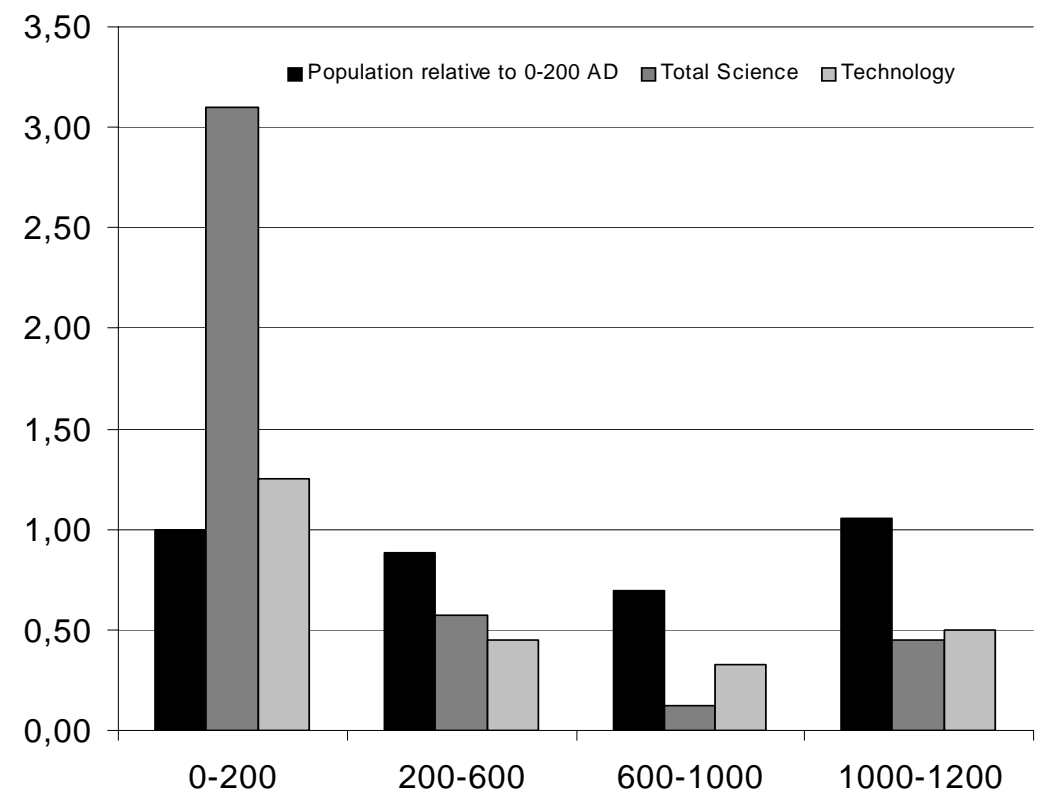

Figure 2: The figure shows the size of population in Europe and average number of major innovations per decade, 0-1200 AD. Sources: European Population is from J.N. Biraben (1979), while data on innovations are from Sorokin (1962)

per decade, within "Total Science" and "Technology" (i.e. applied science), during the period 0 to 1200 A.D. ${ }^{18}$ Like total population, the average number of innovations follows a distinct U-shaped trajectory, from 0 to 1200. Adducing this evidence to the documented examples of lost technologies discussed in the Introduction suggests a long and persistent period of technological regress during the Early Middle Ages.

If indeed technology regressed over the period, then one should also expect to see a major decline in economic activity in its wake, associated with a considerable decline in the division of labor. So did production decline? This is a difficult question to answer directly, since early estimates of European GDP are unavailable. But indirect evidence can be brought to bear. Figure 3 shows

\footnotetext{
${ }^{18}$ One may have a number of reservations about the use of such data in the present context. First, using the gross number of innovations as a proxy for "inventiveness" could be misleading, as some innovations are likely to be more important than others. Hence, just like the use of, say, data on patents, the series will only imperfectly capture the effective flow of new innovations. Second, the exact number of innovations in pre-industrial times are in all likelihood inaccurately measured. With these caveats, the data still represent the best estimates available, and may be reasonably reliable in capturing broad secular changes from one sub-period to the next.
} 
the concentration of lead and copper aerosols in the northern hemisphere. ${ }^{19}$ Following Grantham (1999), one may argue that these numbers provide some independent evidence relating to the evolution of economic activity over the very long run. Moreover the series seems broadly consistent with historians' priors regarding Western economic history. ${ }^{20}$ In the present context it is of particular

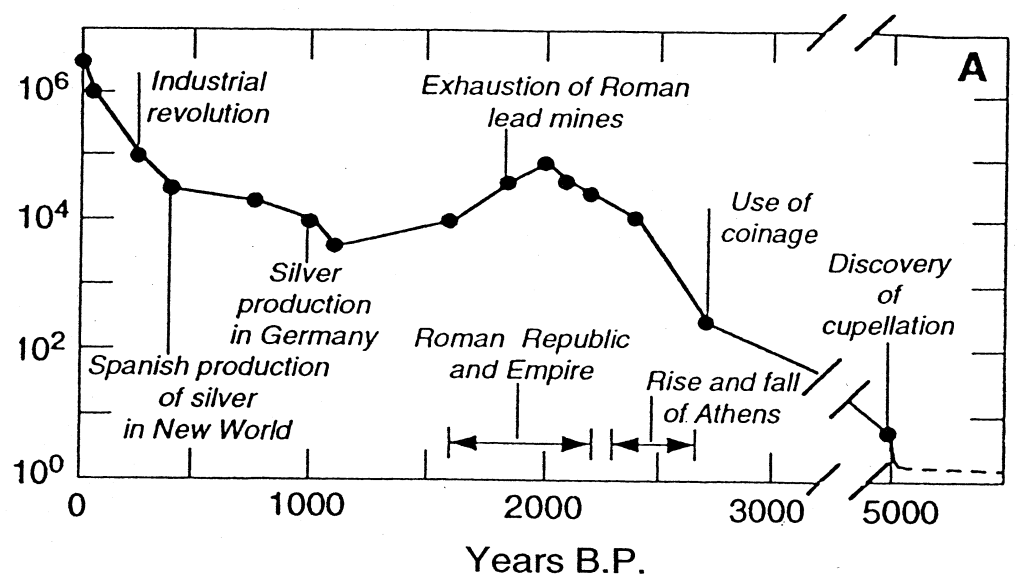

Figure 3: Historical Evolution of Lead Concentration in the Northern Hemisphere. Note: The vertical axis shows the $\mathrm{Pb}$ concentration measured in tons per year. Source: Hong et al (1994)

interest to study the segment of the series following the collapse of the Roman Empire. Economic activity, thus proxied, goes through a major secular decline, as predicted by the model. When the European population starts to recover, production also picks up.

While the above provides indirect evidence in favor of regress, it does not testify to the central mechanism developed in our model to explain the regress, i.e. a shock to aggregate demand restricting the division of labor and thereby causing the relevant technologies to be abandoned and subsequently lost. The following case serves this purpose. The example involves a sector of the economy which traditionally has been viewed to be of first order macroeconomic significance: construction. In ancient Rome fired brick (and quite conceivably marble columns as well) was pre-manufactured and brought to construction sites (Wil-

\footnotetext{
${ }^{19}$ The data derives from an analysis by Hong et al (1994) who study the information contained in the Greenland icecap.

${ }^{20}$ For a discussion of this claim, see Grantham (1999) p. 222-26.
} 
son, 2006). This procedure, reminiscent of the procedures of the contemporary construction business, therefore involved a clear division of labor and allowed for impressive speed in construction. Consider for example the Baths of Caracalla in Rome. The bath building was huge: 228 meters long, 116 meters wide and 38.5 meters in height. It could hold an estimated 1600 bathers, and the complex covered about 13 hectares featuring sumptuous decorations. This entire structure was erected in a mere 5 years, between AD 211 and 216 (Delaine, 1997). After the fall of the Roman Empire, however, we find an apparent cessation of construction in fired brick (and concrete) north of the Alps from about the fifth century (Wilson, 2002).

Declining demand undoubtedly played a crucial role in explaining this fact. Temin (2006), for example, argues that the standard of living in ancient Rome likely was comparable to that of 17th and 18th century Europe; this would suggest a major demand contraction in the aftermath of the Empire's collapse. As a result, construction simply did not take place on the scale and frequency of earlier times, making the quasi-industrial organization of the sector unprofitable. This would explain the loss of such a basic technology as fired brick; the technology was no longer profitable, was therefore not practiced and transmitted. Technological regress was the consequence. In fact, fired brick was by all accounts not used again in construction (in the Northern part of Europe) until the first half of the twelfth century (Wilson, 2006). With fired brick we also see the loss of Pozzalana cement (see the Introduction).

The consequences for productivity in construction were considerable. Whereas major undertakings such as the Baths of Caracalla or Diocletian was completed in less than a decade, Medieval Cathedrals, such as Laon (1160-1225), NotreDame (1163-1250), and Salisbury (1212-1310) often took 50 - 100 years to complete, albeit of comparable size to the baths of Rome. The root cause was a marked reduction in the division of labor, brought on by the demand contraction, which ultimately led to the loss of important technologies like fired brick and Pozzalana cement.

\subsection{Easter Island}

The case of Easter Island offers what is in some respects a more faithful instantiation of our theory. When considering broad areas such as Europe or the Roman Empire it should be borne in mind that their geographical extent was not fixed but kept changing throughout the period in question, and more

important, they were not closed to the outside world; ideas came into society 
through trade and travel. ${ }^{21}$ Therefore, although our model may mirror some of the central processes of knowledge transmission for pre-industrial Europe, there are clearly processes at work which are not part of the model presented above.

Easter Island, on the other hand, is one of the most isolated places in the world; it is situated in the Pacific Ocean, over one thousand miles away from the nearest habitable island (Pitcairn). On this island there is clear evidence of population decline from the time of its original settlement to the time of its first known contact with Europeans in 1722, when the Dutch explorer Jacob Roggveen visited the island. Archaeologists estimate that the population of Easter Island in its heyday was between 7,000 and 20,000 individuals. Roggveen estimated the island's population at 3000 people. The decline continued over the eighteenth and nineteenth centuries. When Captain James Cook arrived in 1774 , the population had shrunk to 2000. Subsequent expeditions by slave traders - who may have been responsible for introducing diseases such as smallpox - decimated the population further. By 1872 only 111 islanders remained. Subsequently the population rose, in part as a result of immigration from Tahiti and Chile.

Our theory suggests that this major decline in population should have been accompanied by technological regress. And indeed, there is rather spectacular evidence of knowledge decay on Easter Island. The best known features of Easter Island are the huge stone statues (or moai) - weighing up to 270 tons - which are erected on stone platforms (or ahu) scattered along the coast line. It is estimated that the ahu and moai were raised over the period $1000-1600$ A.D. (Diamond, 2004). By the time Cook arrived, the tradition of erecting such statues had long since been abandoned. Moreover, those statues that had been erected in the past were now all toppled, and the stone quarry where most were carved was littered with unfinished statues. Local residents had lost not only the knowledge of how to erect such statues, but also the knowledge of how these statues were moved from the quarry where they were constructed to the bases on the coastline on which they were mounted. The dominant legend was that, under the influence of some spiritual power, the statues had walked to the platforms themselves (Brander and Taylor, 1997). ${ }^{22}$

\footnotetext{
${ }^{21}$ As mentioned before, medical advances made by the Greek and Alexandrian civilizations were reintroduced to Western Europe by individuals like Avicenna and Averroes. Both scholars also transmitted their own innovations in medicine.Other examples of ideas coming from abroad are abundant. The decimal system came from the Arabs and the zero from India.

${ }^{22}$ Recent academic research, however, suggests that some oral traditions regarding the statues may have survived. But it is not disputed that the bulk of technical knowledge was lost, and modern archaeologists have performed numerous intriguing experiments on the island to reconstruct how the statues might have originally been errected many centuries ago, See Van Tilburg and Ralston (2005).
} 
Another example of knowledge depreciation in the Polynesian society on Easter Island relates to their boatmaking skills. The first generation of islandinhabitants must have enjoyed an impressive mastery of boatmaking techniques in order to construct vessels capable of colonizing the island. Nevertheless, the Dutch explorer Jacob Roggveen who visited the island in 1722 noted that

... they [the inhabitants of Easter Island] lack the knowledge... for caulking and making tight the great numbers of seam of the canoes, these are accordingly very leaky, for which reason they are compelled to spend half the time in bailing.

- quoted in Diamond, 1995.

A final example of lost knowledge on Easter Island relates to a number of wooden tablets found in the hands of living islanders, bearing ideographic inscriptions. The writing system is of a unique type, but the script is no longer in use, or understood by the islanders (Cottrell, 1964). There is some academic dispute about when the script was invented, with recent research indicating that it may post-date the Spanish landing of 1770 , which may have provided the first contact with a writing system. However, whether the script was invented before the European expeditions or in the eighteenth century, knowledge of the script was certainly lost by the twentieth century, in tandem with the island's continuing population decline.

Extensive research by paleontologists suggests that Easter Island went through an ecological collapse which decimated the indigenous forest that covered the island, thus removing some of the materials necessary for building solid boats and a large portion of the food supply. Brander and Taylor (1997) provide a formal model describing how an isolated society might enter a downward spiral of environmental depletion and population regress. However, while their model elucidates the environmental collapse and population decline that apparently transpired on the island, it does not address the issue of how basic knowledge pertaining to the construction of seaworthy boats and stone megaliths could disappear from the island. Our model complements their story; once the overuse of the ecosystem has reached the point of no return, food and raw materials become scarce and living conditions worsen. The result is starvation, social unrest, and a declining population. Consequently, once ubiquitous technologies are abandoned and eventually disappear. 


\section{Concluding Remarks}

This paper is motivated by what we perceive as two important gaps in the existing theoretical literature on pre-industrial economies. First, the literature does not document or seek to explain the common and persistent phenomenon of technological regress. Second, while the literature contains several reduced form models of the Malthusian economy, and some models that seek to explain growth in terms of increasing specialization, there is no micro-founded theory that generates positive feedback between the evolution of population and the adoption of technology.

Our paper seeks to remedy these omissions by developing a model in which technology is adopted endogenously by profit-maximizing monopolists who each produce a single variety of an intermediate good. An expansion of varieties is interpreted as technological progress; as population grows, so does demand, thereby enabling greater specialization and more division of labor. On the other hand, as technology improves, more output can be produced spurring population growth. Thus there is a positive association between population and technology on the convergence path leading to a stable Malthusian equilibrium.

We argue that the key to understanding technological regress is the much closer identity between technology and human capital in pre-industrial times - especially prior to the printing press and the establishment of formal education during childhood as a norm. In a society in which technology is kept alive by the direct oral transmission of knowledge from one generation to the next, technology is likely to be precarious, and susceptible to regress in the face of negative shocks. We describe a channel by which technology may regress: when a shock acts to reduce productivity or population, certain technologies become unprofitable at the margin. Lack of use leads to certain ideas not being transmitted, thereby resulting in lost knowledge. Further, because population growth is itself constrained by technology, the regress of both technology and population can be very persistent.

We document several examples of technological regress in our paper, as well as the intimate connection between population decline and lost knowledge. We argue that the loss of abundant technologies during the Early Middle Ages in Western Europe, and during the last millennium on Easter Island, may be understood by the mechanisms described in our model.

Future research could build on some of the ideas presented in this paper. For example, the model could be extended in order to generate an endogenous

transition from a Malthusian regime to modern growth, providing - in contrast to the existing literature - a unified theory for such a transition in which 
technological progress is based on micro foundations. Consider, for instance, a trade-off between the quality and quantity of children, assuming that the returns to skills are increasing in the complexity of the economy (instead of the increasing fixed cost per variety). This structure could trigger, at some stage of development, a positive feedback between technology and the formal accumulation of human capital. This would bring about a demographic transition, and an escape from the Malthusian regime, with the accumulation of human capital raising the demand for varieties rather than the accumulation of workers. A skilled population could also imply that the cost of $\mathrm{R} \& \mathrm{D}$ declines and the economy moves from relaying exclusively on random discoveries to active investment in $R \& D$, providing the final step required for the transition to modern growth.

Finally, while the aim of the model is to understand the evolution of technological knowledge in pre-industrial society, the basic mechanism developed is arguably still of some relevance in modern times. For example, the transmission and adoption of knowledge through learning-by-doing may well be characterized by processes similar to those in our model. In this case knowledge transmission would take place between different generations of workers, and could be lost in the event of major changes in the employment structure within countries or regions. An adaptation of our model to such a framework would suggest a positive association between employment density, the division of labor and productivity, ${ }^{23}$ and would also predict that tacit knowledge may be lost in the event of major changes in the employment structure within countries or regions.

\footnotetext{
${ }^{23}$ Consistent with this prediction Ciccone and Hall (1996) find, using data for US states, that a doubling of employment density increases average productivity by 6 percent. In addition, more than half of the variance of output per worker across states can be explained by differences in employment density.
} 


\section{References}

[1] Aghion, P and P. Howitt, 1992. "A Model of Growth through Creative Destruction", Econometrica; 60, p. 323-51

[2] Arrow, K., 1962. The Economic Implications of Learning-by-Doing. Review of Economic Studies, 29, 155-73.

[3] Baker, M., 2007. A Structural Model of the Neolithic Revolution. Working Paper (Hunter College)

[4] Biraben, J.N., 1979. "Essai sur l'evolution du nombre des hommes", Population, 34, p....

[5] Boserup, E., 1965. The Conditions of Agricultural Growth, Adeline Publishing Company, New York.

[6] Brander, J. and S. Taylor, 1997. "The Simple Economics of Easter Island: A Ricardo-Malthus Model of Renewable Resource Use", American Economic Review, Vol. 88, p. 119-138.

[7] Botticini M. and A. Siow. 2005 "The Value of Sons in Pre-modern Economies: A View from the Marriage Market", Boston Universty.

[8] Cervellati, M. and U. Sunde. 2005. "Human Capital Formation, Life Expectancy and the Process of Development," American Economic Review (forthcoming).

[9] Ciccone, A. and R. Hall, 1996. "Productivity and the Density of Economic Activity". American Economic Review; 86, p. 54-70.

[10] Clark, Gregory and Gillian Hamilton. 2004. "Was Pre-Industrial Society Malthusian? Tests from England and New France." Working Paper, UC Davis.

[11] Comin, D., W. Easterly and E. Gong, 2006. Was the Wealth of Nations Determined in 1000 B.C.? Working paper (New York University)

[12] Cottrell, L., 1964. "The Concise Encyclopedia of Archaeology", 2.ed, Hawthorn Books, New York.

[13] de la Croix, D. and Doepke, M. 2003. "Inequality and growth: Why differential fertility matters." American Economic Review, 93, 1091-113. 
[14] Delaine, J., 1997. The Baths of Caracalla: A study in the design, construction and economics of large-scale building projects in the imperial Rome. Journal of Roman Archeology Supplement 25, Portsomuth, R.I.

[15] Diamond, J., 1993. "Ten Thousand Years of Solitude", Discover Magazine.

[16] Diamond, J., 1995."Easter Island's End". Discover Magazine.

[17] Diamond, J., 1997. "Guns, Germs and Steel” New York: W.W. Norton.

[18] Diamond, J., 2004. "Collapse - How Societies choose to fail or succeed". Penguin Books, New York

[19] Doepke, M. 2002. "Accounting for Fertility Decline during the Transition to Growth." UCLA working paper.

[20] Eaton, J. and S. Kortum, 1999. "International Technology Diffusion: Theory and Measurement". International Economic Review; 40, p. 537-70.

[21] Finley, M.I., 1965. Technical Innovation and Economic Progress in the Ancient World. Economic History Review, 18, 29-45.

[22] Fishman, A. and Simhon A. 2002. "The Division of Labor, Inequality and Growth", Journal of Economic Growth, 7, 117-136.

[23] Galor, O., 2005. "From Stagnation to Growth: Unified Growth Theory". in (P. Aghion and S. Durlauf eds.) Handbook of Economic Growth, 171-293, Amsterdam: North Holland.

[24] Galor, O. and D. Weil, 2000. "Population, Technology and Growth: From Malthusian Stagnation to the Demographic Transition and Beyond", American Economic Review, 90, p. 806-828.

[25] Galor, O. and O. Moav, 2002. "Natural Selection and the Origin of Economic Growth", Quarterly Journal of Economics. 117, 1133-1191.

[26] Goodfriend, M. and J. McDermott, 1995. Early Development. American Economic Review; 85, p. 116-33

[27] Grantham, G., 1999. "Contra Ricardo: On the macroeconomics of preindustrial economis. European Review of Economic History; 2, p. 199-232.

[28] Greene, K., 1990. "Perspectives on Roman Technology", Oxford Journal of Archaeology, 22, p.209-19. 
[29] Greene, K, 2000. Technical Innovation and Economic Progress in the Ancient World: M.I. Finley Re-considered. Economic History Review, 53, 2959.

[30] Grossman G. and E. Helpman. 1991. Innovation and Growth in the Global Economy. Cambridge, MIT Press.

[31] Hansen, G. and E. Prescott. 2002. "Malthus to Solow". American Economic Review 92, 1205-17.

[32] Hazan, M. and H. Zoabi. 2004. "Longevity, Fertility and Economic Growth." mimeo. Hebrew University.

[33] Hoffman, P., 1996. "Growth in a Traditional Society: The French Country Side 1440-1815", Princeton University Press.

[34] Hong S., J.P. Candelone and C. Burton, 1994. "Greenland ice evidence of hemispheric lead pollution two millennia ago by Greek and Roman civilization." Science; 265, p. 246-9.

[35] Jones, C.I., 2007. Growth and Ideas, in P. Aghion and S. Durlauf (eds.) Handbook of Economic Growth, Amsterdam: North Holland.

[36] Kelly, M. 1997 "The Dynamics of Smithian Growth" Quarterly Journal of Economics, 112, 939-964.

[37] Kelly M. 2004 "Living Standards and Population Growth: Malthus was Right". University College Dublin.

[38] King, R., 2000. "Brunelleschi's Dome". Penguin Books, New York.

[39] Kortum, S., 1997. "Research, Patenting, and Technological Change", Econometrica; 65, p. 1389-1419

[40] Kremer, M., 1993. "Population Growth and Technological Change: One Million B.C. to 1990" Quarterly Journal of Economics, 108, p. 681-716.

[41] Lagerlof, N. P. 2003. "From Malthus to Modern Growth: Can Epidemics Explain the Three Regimes?" International Economic Review 44, 755-777.

[42] Livi-Bacci, M., 1997. A Concise History of World population, 2.ed., Oxford: Blackwell.

[43] Lucas, R. E. Jr., 2002, "The Industrial Revolution: Past and Future", in: Lucas, R. E. Jr., Lectures on Economic Growth, Cambridge, Massachusetts: Harvard University Press. 
[44] Mainstone, R., 1970. "Brunelleschi's Dome of S. Maria del Fiore and some Related Structures", Transactions of the Newcomen Society 42.

[45] Mokyr, J., 2002. The Gifts of Athena. Princeton University Press.

[46] Nelson and Phelps, 1966. "Investment in Humans, Technological Diffusion, and Economic Growth". American Economic Review, 56, pp. 69-75.

[47] Olsson, O., 2000. "Knowledge as a Set in Idea Space: An Epistemological View on Growth". Journal of Economic Growth, 5, pp. 253-275

[48] Phelps, N, 1966. Models of Technological Progress and the Golden Rule of Research. Review of Economic Studies, 33,133-45.

[49] Romer, P., 1990. "Endogenous Technological Change", Journal of Political Economy, 98, pp. S71-S102.

[50] Simon, J. and R. J. Sullivan, 1989. Population Size, Knowledge Stock, and Other Determinants of Agricultural Publication and Pateting: England, 1541-1850. Explorations in Economic History, 26, 21-44.

[51] Sorokin, P.A., 1962. Social and Cultural Dynamics (2.ed.), Vol. II, The Bedminster Press, New York.

[52] Temin, P., 2006. The Economy of the Early Roman Empire. Journal of Economic Perspectives, 20, p. 133-51.

[53] Tilburg, J.A.V. and T. Ralston, 2005. "Megaliths and Mariners: Experimental Archaeology on Easter Island.", in K.L. Johnson, ed., Onward and Upward: Essays in Honor of Clement W. Meighan, Lanham, MD: University Press of America, 2005.

[54] Weitzman, M., 1998."Recombinant Growth". Quarterly Journal of Economics; 113, p. 331-60.

[55] Wilson, A., 2002. Machines, Power and the Ancient Economy. The Journal of Roman Studies, 92, p. 1-32.

[56] Wilson, A., 2006. The economic impact of technological advances in the Roman construction industry, in E. Lo Cascio (ed.) Innovazione tecnica e progresso economico nel mondo romano. (Pragmateiai). Bari, Edipuglia, p. $225-36$. 